\title{
What are the environmental impacts of property rights regimes in forests, fisheries and rangelands? a systematic review protocol
}

\author{
Maria Ojanen ${ }^{1 *}$, Daniel C Miller ${ }^{2}$, Wen Zhou' ${ }^{1}$ Baruani Mshale ${ }^{2}$, Esther Mwangi ${ }^{1}$ and Gillian Petrokofsky ${ }^{3}$
}

\begin{abstract}
Background: Property rights to natural resources comprise a major policy instrument for those seeking to advance sustainable resource use and conservation. Despite decades of policy experimentation and empirical research, however, systematic understanding of the influence of different property rights regimes on resource and environmental outcomes remains elusive. A large, diverse, and rapidly growing body of literature investigates the links between property regimes and environmental outcomes, but has not synthesized theoretical and policy insights within specific resource systems and especially across resource systems. Here we provide a protocol for conducting a systematic review that will gather empirical evidence over the past two decades on this topic. We will ask the following questions: a) What are the environmental impacts of different property regimes in forests, fisheries, and rangelands? b) Which property regimes are associated with positive, negative or neutral environmental outcomes? c) How do those environmental outcomes compare within and across resource systems and regions?

Methods: We will assess current knowledge of the environmental impacts of property rights regimes in three resource systems in developing countries: forests, fisheries and rangelands. These resource systems represent differing levels of resource mobility and variability and capture much of the range of ecosystem types found across the globe. The review will use a bundle of rights approach to assess the impacts of three main property regimesstate, private, and community - as well as mixed property regimes that involve some combination of these three. Assessment of the impacts of property rights regimes across a range of different resource systems and ecosystem types will enable exploration of commonalities and differences across these systems. Our analysis will emphasize major insights while highlighting important gaps in current research.
\end{abstract}

Keywords: Property rights, Tenure, Bundle of rights, Forests, Fisheries, Rangelands, Environmental impacts

\section{Background}

Debate over the effects of different property regimes on natural resource systems has long been controversial, incited by Hardin's [1] thesis that common pool resources will inevitably suffer from overexploitation and degradation. Moreover, the dominant paradigm long held that government or private property was required for conservation and sustainable resource use. In response, a large body of scholarship has demonstrated that widening the breadth of property rights held by local-level actors in

\footnotetext{
*Correspondence: m.ojanen@cgiar.org

${ }^{1}$ Center for International Forestry Research (CIFOR), Jalan CIFOR, Situ Gede, Sindang Barang, Bogor (Barat) 16115, Indonesia

Full list of author information is available at the end of the article
}

common property regimes can lead to more efficient and effective outcomes for resource sustainability [2-4]. Devolution of property rights to community and local level actors has since been used as an instrument for achieving goals as disparate as poverty alleviation [5], gender equity [6], resource conservation [7], and climate change mitigation [8]. Of course, states have also retained or claimed new property rights or allocated them to private sector actors in the name of these same goals [9].

A large, diverse, and rapidly growing body of literature has investigated the links between these property regime transitions and their environmental outcomes. A significant portion of the literature assesses recent decentralization policies, broadly described as tenure reforms, that transfer 
decision-making rights and authority from central to local governments or formally recognized existing de facto rights at the local level. Another branch of literature assesses the outcomes of initiatives for community-based natural resource management and community-based conservation. Thus far, the literature has yielded mixed findings on resource conditions and sustainability such as biodiversity loss, forest cover change [10], fisheries decline [11], and rangeland degradation [12]. Despite the expanding literature, little has been done to account for the variation in environmental impacts which limits advances in policy making and management intervention. Moreover existing syntheses and reviews on property regimes focus mostly on community based management [13-15], although natural resources are governed through state, private and common property regimes across diverse ecological and political systems. Broadening the scope to examine outcomes in state and private property regimes can give us valuable theoretical and policy insights on similarities and systematic differences within and across resource systems. The increasing emphasis on landscape approaches and thinking beyond individual resource systems makes informing policy and practice at multiple scales of governance even more crucial [16].

This systematic review will synthesize extant empirical evidence of the impacts of different property rights regimes on environmental outcomes in three resource systems at local to regional scales in developing countries: forests, fisheries and rangelands. Although this review will limit itself to the assessment of environmental outcomes, it will also consider context and mediating factors and will aim to determine more systematically which contextual elements matter most decisively. Accounting for the context is especially important since property regime transitions are not always unidirectional nor fully realized, leaving ample room for discrepancies between existing de facto and newly inscribed de jure regimes and conflicts between recognized and unrecognized actors [17].

\section{Objectives of the review}

The review seeks to answer the following primary question:

- What are the environmental impacts of different property regimes in forests, fisheries, and rangelands in developing countries?

It also poses two secondary questions:

- Which property regimes are associated with positive, negative or neutral environmental outcomes?

- How do those environmental outcomes compare within and across resource systems and world regions?
Assessment of the impacts of property rights regimes across a range of different resource systems and ecosystem types enables exploration of commonalities and differences across these systems. As the review is interested in looking both short term and long term results of property rights interventions, both terms impact as well as outcome will feature in the review. Appendix explains in detail the definitions of other key terms used in this review.

This review adopts a PICO (Population-InterventionComparator-Outcomes) framework to structure analysis of these research questions [18], summarized in Table 1.

\section{Population}

The population refers to the three resource systems: forests, fisheries and rangelands (see Appendix for operational definitions of each of these systems). We have chosen these systems due to the importance of the ecosystem services they provide as well as their broad geographical coverage, which includes much of the range of ecosystem types found across the globe. These three resource systems also represent differing levels of resource mobility and variability, thus introducing important variation in the biophysical nature of the resources they provide. We will exclude other natural systems as well as heavily human-modified systems such as irrigation systems and cities.

\section{Intervention}

The intervention refers to the introduction of a particular property rights regime, whether state, private, and community or some combination of these (mixed regimes). The intervention could also be the establishment of a protected area for the explicit objective of resource conservation, although these cases will be treated separately. The review uses a bundle of rights approach, introduced by Schlager and Ostrom [19], to examine how the distribution of access, withdrawal, management, exclusion, and alienation rights in state, private, community, and mixed property regimes affects resource outcomes. In addition, this review considers the right to income from resource use as part of the bundle of rights that comprise a property regime, defined as a system of rules governing access to and control over resources [20], and specifying permissible and forbidden actions in relation to use and management, responsibilities and obligations [2,21]. Also in the case of protected areas, the bundle of rights approach will be used as it captures well the different joint/mixed property rights arrangements present in protected areas.

\section{Comparator}

This review compares environmental outcomes based on analysis of studies using the following three methodologies: change from before to after the intervention (temporal change), case control studies (with-without comparison), 
Table 1 Research framework for Population-Intervention-Comparator-Outcomes (PICO)

\begin{tabular}{|c|c|c|c|}
\hline $\begin{array}{l}\text { POPULATION } \\
\text { Resource systems }\end{array}$ & $\begin{array}{l}\text { INTERVENTION } \\
\text { Property regimes }\end{array}$ & COMPARATOR & OUTCOME MEASURES \\
\hline \multirow[t]{2}{*}{ Forests } & State & $\begin{array}{l}\text { Before and after intervention } \\
\text { (temporal dimension) }\end{array}$ & \multirow{2}{*}{$\begin{array}{l}\text { Species diversity and abundance, forest cover, forest } \\
\text { condition, tree density, biomass, carbon sequestration, } \\
\text { measures of land degradation and desertification, } \\
\text { forest loss, land conversion, measures of disturbances } \\
\text { such as number of cut stumps, number of invasive } \\
\text { species, etc. }\end{array}$} \\
\hline & OR Private & $\begin{array}{l}\text { OR With and without the intervention, } \\
\text { from a similar setting (spatial dimension) }\end{array}$ & \\
\hline Fisheries & OR Community & $\begin{array}{l}\text { OR Both before and after AND with } \\
\text { and without intervention (BACI) }\end{array}$ & $\begin{array}{l}\text { Abundance of fish, fish size, diversity of species, biomass, } \\
\text { health of coral, water quality, reproductive indicators, etc. }\end{array}$ \\
\hline Rangelands & OR Mixed & & $\begin{array}{l}\text { Species diversity and abundance, plant and bare ground } \\
\text { cover, proportion of different species, soil indicators, } \\
\text { carbon sequestration, biomass, soil nutrient levels, number } \\
\text { of supported animals etc. }\end{array}$ \\
\hline
\end{tabular}

or a combination of both (a BACI-before-after-controlimpact-design). This latter design is based on data from before and after the intervention of interest and in sites where the intervention took place and matched control sites that are similar as possible to the intervention sites except that there was no intervention. The BACI approach seeks to rule out potentially confounding effects and to increase confidence that outcomes observed were due to the intervention [22].

Reviewers anticipate that control sites will often be characterized by open access regimes, but they may be any of the different property rights regimes identified as long as they were present in both treatment and control sites prior to the treatment (change in property rights regime). Moreover, the socioeconomic and environmental baselines of control and treatment sites should be of sufficient similarity such that divergent environmental results, if any, are attributable to the intervention or named contextual factors. In the case of protected areas, the comparison will need to present temporal comparison (beforeafter) within the protected area or spatial comparison with another regime outside the protected area.

\section{Outcomes}

The outcome of interest in this analysis consists of qualitative and quantitative changes in environmental measures, which may vary by resource system. Table 1 includes illustrative outcome indicators likely to be found in relevant studies. Based on information on change and/or difference in these indicators in each study, reviewers will determine whether the environmental outcomes associated with different property regimes were positive, negative or neutral. Both the original outcome measures reported in the studies under review and the reviewers' assessment of environmental outcomes will be recorded.

\section{Methods}

\section{Searches}

To capture as unbiased and comprehensive a set of relevant literature as possible within the constraints of the review budget, time allocation, and familiarity with languages, the search will be conducted in the databases shown in Table 2. Searches conducted on Google and Google Scholar will be limited to the first 200 hits retrieved. Any links will be followed only once from the original hit. Previous systematic reviews on the topic [13,15,23-25] and literature reviews assessing tenure and environmental outcomes that are identified by the search will be hand-searched to identify further relevant studies.

Electronic search strategies have been tested using the ISI Web of Knowledge, CAB Abstracts and Google Scholar. This testing process has been documented and informs this protocol (see Appendix). The following search terms will be applied to the different databases, with search term and database specific modifications. As the operation of websites and database-specific search engines varies greatly, the reviewers will modify their search and search terms for each database in order to retrieve results that balance the needs for sensitivity and specificity to the review question [18]. If use of several search terms is impossible, the reviewers will take advantage of available topic-relevant key words and publication categorizations. Reviewers will also adjust for different word permutations or suffixes through the use of wildcard symbols, where applicable. The development and implementation of the search strategy will be recorded, including the testing process, number of hits, relevance of the results and the date of search. The reviewers will also contact individual organizations (through librarians or other information specialists) for further guidance.

To reduce language bias that may be associated with limiting the review to English language publications, the search will be also conducted in French and Spanish. Search in French and Spanish will be conducted in Google, Google Scholar as well as in primary databases where applicable. In addition, reviewers will conduct search for grey literature within institutions and NGOs whose main language is French or Spanish, e.g. CIRAD (French) and Facultad Latinoamericana de Ciencias Sociales (Spanish). In order to take benefit from all the 
Table 2 The list of databases and other data sources for the systematic review

\begin{tabular}{ll}
\hline Primary research databases & \\
\hline Agris & http://agris.fao.org/ \\
Agricola & http://agricola.nal.usda.gov/ \\
CAB Abstracts & http://www.cabdirect.org/ \\
SciELO - Scientific Electronic & http://www.scielo.org/ \\
Library Online & \\
Scopus & http://www.scopus.com/ \\
Web of Knowledge & http://www.webofknowledge.com
\end{tabular}

General web search engines

Google

www.google.com

Google Scholar

www.scholar.google.com

Research institutes, research networks and universities

Agriculture Network Information Center (AgNIC) at Colorado State

\section{Center for International}

Forestry Research

Centro de Informacion de Recursos Naturales

Centro de Investigaciones Pesqueras MINAL

CGIAR System-wide Program on Collective Action and Property Rights

CIRAD

Coalition of European Lobbies for Eastern African African Pastoralism (CELEP)

Digital Library of the Commons

Facultad Latinoamericana de Ciencias Sociales (FLACSO)

Fondo de Conservacion de Bosques Tropicales Paraguay

Institut de recherché pour le développement (IRD)

Institut des sciences humaines et sociales (INSHS) du centre national pour la recherche scientifique (CNRS) Instituto del Mar del Peru

Instituto Mamiraua

International Food Policy Research Institute

International Institute for Fisheries Economics and Trade (IIFET)

International Livestock Research institute

Lincoln Institute of Land Policy http://lib.colostate.edu/agnic

http://www.cifor.org

http://www.ciren.cl/web/

http://www.ecured.cu/index.php/ Centro_de_Investigaciones_Pesqueras http://www.capri.cgiar.org/

http://www.cirad.fr/

http://www.celep.info

http://dlc.dlib.indiana.edu/dlc/

http://www.flacso.org/

http://www

fondodeconservaciondebosques.org.py/

www.ird.fr

http://www.cnrs.fr/inshs/recherche/ librairie/176.htm

http://www.imarpe.pe/imarpe/

http://www.mamiraua.org.br/pt-br

http://ifpri.org

http://oregonstate.edu/dept/iifet/

http://ilri.org

http://www.lincolninst.edu/
Table 2 The list of databases and other data sources for the systematic review (Continued)

Nelson Institute Land Tenure http://www.nelson.wisc.edu/ltc/ Center

PLAAS

http://www.plaas.org.za/

The Organization for Social Science Research in Eastern and Southern Africa (OSSREA)

Thèses.fr (French master thesis and $\mathrm{PhD}$ )

Universidad de los Andes (Colombia)

Universidad Nacional

Autonoma de Mexico

http://publications.ossrea.net/

University of Wageningen library

http://www.thèses.fr

http://www.uniandes.edu.co/

http://www.unam.mx/

http://www.wageningenur.nl/

Western Indian Ocean Marine http://www.wiomsa.org

Science Association (WIOMSA)

World Agroforestry Center

http://www.worldagroforestrycentre.org/

WorldFish

http://worldfishcenter.org

\section{International organizations and donor agencies}

US Agency for International http://usaid.gov Development (USAID)

African development bank http://www.afdb.org/en/documents/ database (AfDB)

African Journals online

Amazonia

Asian Development Bank (ADB)

Banco interamericano de desarrollo (BID)

Centro Peruano De Estudios Sociales (CEPES)

\section{DIVERSITAS}

EuropeAid european union cooperation and development agency

European Tropical Forest Research Network

Food and Agriculture Organization (FAO)

German GIZ Gesselschaft fur Internationale

Zusammenarbeit

Institute of Development Studies

Instituto Brasileiro de Geografia e Estatica

International GeosphereBiosphere Program (IGBP)

International Institute for Environment and Development (IIED) http://www.ajol.info/

http://amazonia.org.br/

http://www.adb.org/publications

http://publications.iadb.org

http://www.cepes.org.pe/portal/

http://www.diversitas-international.org

http://ec.europa.eu/europeaid/ multimedia/index_en.htm

http://www.etfrn.org

http://www.fao.org

https://www.giz.de/en/mediacenter/ library.html

http://www.eldis.org/go/topics/resourceguides/environment

http://www.ibge.gov.br/english/

http://www.igbp.net

http://www.iied.org

http://www.nead.gov.br/portal/nead/ 
Table 2 The list of databases and other data sources for the systematic review (Continued)

\begin{tabular}{|c|c|}
\hline $\begin{array}{l}\text { ODI overseas development } \\
\text { institute }\end{array}$ & http://www.odi.org.uk/publications \\
\hline $\begin{array}{l}\text { Permanent Institution of the } \\
\text { International Federation of } \\
\text { Surveyors }\end{array}$ & http://www.oicrf.org/ \\
\hline $\begin{array}{l}\text { The International Human } \\
\text { Dimension Programme on } \\
\text { Global Environmental Change } \\
\text { (IHDP) }\end{array}$ & http://www.ihdp.unu.edu \\
\hline $\begin{array}{l}\text { The Organisation for } \\
\text { Economic Co-operation and } \\
\text { Development (OECD) }\end{array}$ & http://www.oecd.org/ \\
\hline The World Bank & http://worldbank.org \\
\hline Tierra Fundacion & http://www.ftierra.org/ \\
\hline $\begin{array}{l}\text { UK department for } \\
\text { international development }\end{array}$ & $\begin{array}{l}\text { https://www.gov.uk/government/ } \\
\text { publications }\end{array}$ \\
\hline UNESCO & $\begin{array}{l}\text { http://www.unesco.org/new/fr/unesco/ } \\
\text { resources/publications/ }\end{array}$ \\
\hline $\begin{array}{l}\text { United Nations Convention } \\
\text { to Combat Desertification } \\
\text { (UNCCD) }\end{array}$ & http://www.unccd.int/ \\
\hline $\begin{array}{l}\text { United Nations Development } \\
\text { Programme (UNDP) }\end{array}$ & http://www.undp.org \\
\hline $\begin{array}{l}\text { United Nations Environment } \\
\text { Programme (UNEP) }\end{array}$ & http://www.unep.org/ \\
\hline United Nations University & http://unu.edu/ \\
\hline $\begin{array}{l}\text { World bank and IMF library } \\
\text { (JOLI) }\end{array}$ & $\begin{array}{l}\text { http://external.worldbankimflib.org/ } \\
\text { external.htm }\end{array}$ \\
\hline $\begin{array}{l}\text { World Resources Institute } \\
\text { (WRI) }\end{array}$ & http://www.wri.org/ \\
\hline \multicolumn{2}{|l|}{ NGOs, Think Tanks } \\
\hline aGter & $\begin{array}{l}\text { http://www.agter.asso.fr/rubrique139_fr. } \\
\text { html }\end{array}$ \\
\hline $\begin{array}{l}\text { Alimenterre platform and } \\
\text { ressources }\end{array}$ & $\begin{array}{l}\text { http://www.alimenterre.org/recherche/ } \\
\text { r\%C3\%A9gime\%20foncier }\end{array}$ \\
\hline $\begin{array}{l}\text { AVSF agronomes et } \\
\text { vétérinaires sans frontiers }\end{array}$ & $\begin{array}{l}\text { http://www.avsf.org/fr/recherche_ } \\
\text { avancee }\end{array}$ \\
\hline $\begin{array}{l}\text { Community Forestry } \\
\text { International }\end{array}$ & $\begin{array}{l}\text { http://www. } \\
\text { communityforestryinternational.org/ }\end{array}$ \\
\hline Conservation Gateway (TNC) & http://www.conservationgateway.org \\
\hline Conservation International & http://www.science2action.org \\
\hline CORDIO & http://cordioea.net/ \\
\hline Equator initiative & http://www.equatorinitiative.org/ \\
\hline $\begin{array}{l}\text { GRAF action and research on } \\
\text { tenure group in the Sahel }\end{array}$ & $\begin{array}{l}\text { http://www.graf-bf.org/spip.php? } \\
\text { rubrique4 }\end{array}$ \\
\hline International Land coalition & http://www.landcoalition.org/ \\
\hline $\begin{array}{l}\text { International Union for } \\
\text { Conservation of Nature } \\
\text { (IUCN) }\end{array}$ & $\begin{array}{l}\text { http://www.iucn.org/wisp/resources/ } \\
\text { publications }\end{array}$ \\
\hline Landesa & http://www.landesa.org/ \\
\hline Landportal & http://landportal.info/ \\
\hline $\begin{array}{l}\text { le Hub Rural (west and } \\
\text { central africa platform) }\end{array}$ & $\begin{array}{l}\text { http://www.hubrural.org/ } \\
\text { base_documentaire.html?lang=fr }\end{array}$ \\
\hline
\end{tabular}

Table 2 The list of databases and other data sources for the systematic review (Continued)

\begin{tabular}{ll}
\hline LMMA Network & http://www.Immanetwork.org \\
Oakland Institute & http://www.oaklandinstitute.org/ \\
Rainforest Portal & http://www.rainforestportal.org/ \\
ReefBase & http://www.reefbase.org/pacific \\
Resources for the Future & http://www.rff.org \\
Rights and Resources & www.rightsandresources.org \\
Initiative & \\
Tenure observatory of & http://www.observatoire-foncier.mg/ \\
$\begin{array}{l}\text { Madagascar (observatoire } \\
\text { foncier de madagascar) }\end{array}$ & \\
The Center for People and & http://www.recoftc.org \\
Forests (RECOFTC) & \\
Tropenbos International & http://www.tropenbos.org \\
\hline
\end{tabular}

languages mastered by the review team an additional search in Indonesian will be conducted where applicable. The databases will be searched with following English terms and with their French, Spanish and Indonesian translations.

Population terms: Forest, fish, marine, grassland, pastoralist, pasture, rangeland

Intervention terms: Collective, common, community, customary, government, public, private, small-scale, state, public, private, company, concession, participatory, collaborative, co-operative, co-manage, shared, joint

Intervention-related terms: Decentralization, tenure, reform, allocation, ownership, property right, property rights, property regime, property system,

management, access, harvest, open access

Examples how search words will be combined are presented in Table 3. Searches will also be conducted using different institutional accesses (CIFOR, University of Michigan and University of Oxford) to take advantage of different subscription databases.

\section{Study inclusion and exclusion criteria}

Inclusion criteria will be applied to select the relevant articles captured by the search. Inclusion criteria will be applied to the titles and abstracts of articles. Studies will be included if they fulfill the following criteria.

\section{Type of study}

Only primary empirical literature will be included, such as case studies, case-control studies and cohort studies, including quantitative and qualitative research.

Subjects studied: We will include studies that asses any property regime associated with forests, fisheries and rangelands. Studies need to assess outcomes from before/ after change in a property regime (temporal dimension), 
Table 3 List of search terms in Google Scholar ${ }^{(1)}$, WOK ${ }^{(1)}$ and CAB ${ }^{(1)}$

\begin{tabular}{|c|c|}
\hline $\begin{array}{l}\text { Google Scholar } \\
\text { (english) }\end{array}$ & $\begin{array}{l}\text { (fish OR fisheries OR rangeland OR grassland OR pasture OR forest) AND (common OR community OR government } \\
\text { OR state OR public OR private) AND (tenure OR property OR rights) Search results were limited to } 1990 \text { onwards }\end{array}$ \\
\hline \multirow[t]{4}{*}{$\overline{\text { WOK }}$} & $\begin{array}{l}\text { Topic=(forest* or fish* or marine or grassland* or pastoralis* or pasture or rangeland*) AND Topic=(decentraliz* or tenure or } \\
\text { reform* or allocation or ownership or "property right"or "property rights" or "property regime" or "property system" or manag* } \\
\text { or access or harvest* or open?access) AND Topic=(collective or comm?n* or small?scale or customary or state or public or } \\
\text { privat* or compan* or concession* or participat* or collaborative or co?operative or co-manage* or shared or joint) AND } \\
\text { Topic=(Armenia* or Bhutan* or Bolivia* or Cameroon* or "Cape Verde" or "Côte d'Ivoire" or "Ivory Coast" or Djibouti* or Egypt* } \\
\text { or "El Salvador" or Georgia* or Ghana* or Guatemala* or Guyan* or Hondura* or Indonesia* or India* or Kiribati*or Lao* or } \\
\text { Lesotho* or Mauritania*or Micronesia* or Mongolia*or Morocc* or Nicaragua*or Nigeria* or Pakistan* or Papua* or Paraguay* } \\
\text { or Philippin* or Samoa* or "Sao Tome" or Senegal* or "Solomon Islands" or "Sri Lanka" or Sudan* or Swaziland*) OR }\end{array}$ \\
\hline & $\begin{array}{l}\text { OR Topic=(Afghan* or Bangladesh* or Benin* or Burkina* or Burundi* or Cambodia* or Central African Republic or Chad* or } \\
\text { Comoro* or Congo* or Eritrea*or Ethiopia* or Gambia* or Guinea* or Haiti* or Kenya* or Korea* or Kyrgyz* or Liberia* or } \\
\text { Madagascar* or Malagasy* or Malawi* or Mali* or Mozambique* or Myanmar* or Burma* or Nepal* or Niger or Rwanda* or } \\
\text { Sierra Leone or Somali* or Sudan* or Tajikistan* or Tanzania* or Togo* or Uganda* or Zimbabwe*) }\end{array}$ \\
\hline & $\begin{array}{l}\text { OR Topic=(Angola* or Algeria* or Samoa* or Argentina* or Azerbaijan* or Beliz* or Botswana* or Brazil* or Chin* or Colombia* } \\
\text { or "Costa Rica" or "Costa Rican" or Cuba* or Dominica* or Equatorian* or Ecuador* or Fiji* or Gabon* or Grenad* or Iran* or } \\
\text { Iraq* or Jamaica* or Jordan* or Kazak* or Leban* or Libya* or Malaysia* or Maldives or "Marshall Islands" or Mayotte or } \\
\text { Mauritius or Mexic* or Namibia* or Palau* or Panama* or Peru * or Seychell* or "South Africa" or "St! Lucia" or "St. Vincent" or } \\
\text { Suriname* or Thai* or Tonga* or Tunisia* or Turk* or Turkmenistan* or Tuvalu* or Venezuela*) }\end{array}$ \\
\hline & Search results were limited to $1990-2013$ \\
\hline
\end{tabular}
regime" OR "property system" OR "common property resources")) AND yr:[1990 TO 2014]

OR AND subject:(forest* OR fish* OR marine OR rangeland* OR grassland* OR pasture*) AND subject:("tenure systems" OR "property rights" OR "property regime" OR "property system" OR "common property resources") AND yr:[1990 TO 2014]

\footnotetext{
${ }^{(1)}$ The symbol asterisk (*) is a truncation operator and presents zero or more characters in a search term. Forest* would thus include forests, forestry, forester, forestal etc. It was not used in Google Scholar as the search engine does not recognize truncation symbols.
}

assess outcomes from different regimes in a with/without setting (spatial dimension), or a combination of these (BACI). Papers reviewing environmental outcomes without a reference to a specific property regime will not be included, nor will studies of plantation forests and aquaculture. The review will exclude commentary and position papers.

\section{Outcomes}

Studies must measure and/or qualitatively assess change and/or difference in environmental outcomes as illustrated Table 1.

\section{Regional focus}

Studies will only be included if the research focuses on the developing countries of Latin America and the Caribbean, Africa, and Asia and the Pacific (see Appendix for complete list of countries). Developing countries are those defined as either low or middle income according to the World Bank. We will use this classification rather than others (such as OECD/non-OECD), as the division into low and middle income countries enables synthesis that includes economic context.

\section{Timeframe}

Studies need to have been published between 1990-present.

Based on the inclusion criteria described above, the review will use a three-step process to identify studies for inclusion.
(1) Studies clearly not relevant will be excluded on the basis of titles only

(2) Studies with potentially relevant titles will be assessed using their abstracts.

(3) Any potentially relevant study that gets through stages 1 and 2 will be collected and assessed for inclusion as full text.

A kappa statistic - the standard measurement used in previous systematic reviews [15],[13] to check for consistency - will be calculated for all reviewers involved in screening prior to work on inclusion. This has been trialed during protocol development and moderate to high levels of consistency have been achieved during these trials. Once satisfactory kappa statistics has been achieved for our final set of screeners, reviewers will determine separately which papers fulfill the inclusion criteria at each step for batches of publications.

To check for consistency of the selection at each stage, two authors will review a $10 \%$ random subsample of abstracts and full texts at these screening stages. If too many differences between inclusion and exclusion are perceived, further discussion on interpretations and possible revision of the criteria will be done iteratively until a satisfactory kappa figure is achieved, following best practice with other published systematic reviews. We will also record the reasons for exclusion at full text for each article and provide this information as an appendix in the final systematic review. 
Potential effect modifiers and reasons for heterogeneity The following potential effect modifiers related to the environmental, socio-economic, and political context of the intervention will be considered and recorded:

\section{Environmental context}

- Location

- Ecosystem type

- Spatial extent of resource area

- Elevation

- Accessibility

- Baseline resource condition

- Existence of external environmental management intervention

\section{Socio-economic context}

- Population density in study/resource area

- Change in population in study/resource area

- Local and external market demand on resource

- Economic inequality (information stated in study, GINI coefficient, etc.)

- Presence of education initiatives

- Presence of infrastructure

\section{Political context}

- Nature of political regime (democracy, authoritarian, totalitarian)

- Decentralization (whether decentralized or decentralizing; year decentralization process began; extent of decentralization: advanced; not advanced)

- Corruption (no corruption, low corruption, high corruption according to study; other measures of corruption, e.g. WGI, Transparency International)

The following additional characteristics of property regime interventions will also be noted where information is available in the study:

- Clarity of rights

- Stability of rights

- Level of enforcement

- Legitimacy of decision-making authority over rights

- Gender equality of property rights

- External support: whether the regime is supported by external actors, such as NGOs, donors, or companies

- Formal protected area: Whether property rights regime applies to a legally protected area

The variables listed above were identified based on consultation with experts in the field of property rights and natural resource governance and knowledge among the review team of the empirical and theoretical literature relevant to this review. The reviewers have winnowed the number of potentially relevant variables to a manageable set that addresses especially salient hypotheses in this area of inquiry.

\section{Study quality assessment}

Once all relevant articles have been identified, full texts will be reviewed to assess study quality according to the questions below. These questions are based on recommendations by the Cochrane Collaboration [26] as well as previous reviews [13], but have been modified to account for the realities of available research on the impacts of property rights, which is characterized by an extensive number of qualitative case studies [27]. Two researchers will code a $10 \%$ random sample of articles to test the coding protocol and intercoder reliability. Kappa values will be calculated to assess agreement and if agreement is less than $50 \%$ the researchers will adjust the coding protocol to increase clarity and agreement.

\section{Questions and coding system used to guide the quality assessment}

1. Clarity and replicability of methods: Are the research methods clearly presented so that the research could be repeated? [clear and repeatable $=1$, not clear and repeatable $=0$ ]

2. Appropriateness of methods: Are the research methods appropriate for addressing the research question(s)? [appropriate $=1$, not appropriate $=0$ ]

3. Study design category: Which of the following categories is most appropriate to describe this study? [cross sectional study or time series study $=0$; case control study $=1$; controlled before-and-after (BACI) study = 2]

4. Sample size: Is sample size explained and well justified? [yes $=1$, no $=0$ ]

5. Confounding factors: Did the study account for and seek to minimize the effects of potential confounding factors in its design and analysis? $[$ yes $=1$, no $=0]$

Studies will be assessed based on the above quality categories. The quality of each study will be scored based on the above questions, with results recorded in a separate Excel spreadsheet. Explanations for each decision will be recorded in order to keep the process transparent and repeatable.

However, for those identified studies that fail the quality requirements (scoring 0 on our quality assessment scale), a sensitivity analysis will be conducted during the data analysis stage to determine the effect of their 
inclusion on the results of our systematic review. Should their results be markedly different from those of studies that met quality criteria, they will be discarded from the final synthesis. These studies will be available for analysis if the sensitivity analysis indicates that the review would be richer with their inclusion. We will in any case capture the numbers that have been assessed at different quality levels in graphical representations of the state of the evidence base.

In addition, reviewers will also record the type of the data analysis used in each case study according to the following typology:

- qualitative analysis

- quantitative analysis -descriptive or observational statistics

- quantitative analysis - analysis of variance, t-test, statistical correlation or other bivariate analysis

- quantitative analysis-multivariate regression or other multivariate analysis

\section{Data extraction strategy}

Data on individual property regime interventions and their environmental outcomes will be collected in a data extraction matrix using an Excel spreadsheet. This will include information on the resource systems in which the property rights regime is implemented, the de jure and de facto nature of the regime as determined by the specific property rights accorded under each regime, stated objectives of the property rights regime intervention, intervention year, study year, the environmental outcomes of regime interventions, and confounding factors that may explain the nature and variation of the outcomes of the regime, including baseline environmental characteristics, external regime characteristics that may further enable the outcomes of an intervention (such as the stability of rights held and level of enforcement of the regime), and characteristics of the socioeconomic and political context. A coding protocol has been developed and it is presented in Table 4. As the data extraction advances, other coding systems will be developed (e.g. resource systems, countries and geographic regions).

To fully address geographic differences, we will collect not only country data but also data within subregions, and further take into account the varying ecosystem types within the broad categorizations of forests, rangelands, and fisheries by documenting individual ecosystem type. Should a paper present multiple studies of different property regimes, each of these will be recorded individually within the data extraction sheet. Thus if spatial comparisons of two regimes or comparisons of outcomes from multiple regimes are made, each regime will present an individual data entry.

\section{Table 4 Initial coding protocol for data extraction}

\begin{tabular}{|c|c|}
\hline - bundle of rights & $\begin{array}{l}S=\text { State } P=\text { Private } C=\text { Community } \\
0=\text { undefined } 1=\text { right defined }\end{array}$ \\
\hline - clarity of rights & clear $=1$, unclear $=0$ \\
\hline - stability of rights & stable $=1$, unstable $=0$ \\
\hline - level of enforcement & $\begin{array}{l}\text { no enforcement }=0 \text {, low enforcement }=1 \text {, } \\
\text { high enforcement }=2\end{array}$ \\
\hline $\begin{array}{l}\text { - legitimacy of decision } \\
\text { making authority over } \\
\text { rights }\end{array}$ & legitimate $=1$, not legitimate $=0$ \\
\hline - external support & yes $=1$, no $=0$ \\
\hline - formally protected area $x$ & yes $=1$, no $=0$ \\
\hline - corruption & high/low/no \\
\hline - environmental condition & good/fair/poor \\
\hline - environmental change & positive, negative, no change \\
\hline
\end{tabular}

\section{Data synthesis and presentation}

Our data synthesis will be based on the information categories mentioned in "Potential effect modifiers and reasons for heterogeneity" as well as "Data extraction strategy categories." We will synthesize the results on environmental outcomes across different resource systems, ecosystem types and geographical regions. We will synthesize the environmental results considering the allocation of bundle of rights as well as the context factors. A series of matrices will be deployed to illustrate: a) how environmental outcomes may vary according to the bundle of rights allocation as well as the institutional arrangements that support (or not) the rights regimes, for example, security of rights as determined by enforcement, clarity, stability and legitimacy of authority; b) how contextual factors influence environmental outcomes; c) how environmental outcomes vary with resource type; and d) how a to c above vary in different geographical locations. The synthesis matrices will be accompanied by a narrative. We will also include a note on the performance of different methodologies in providing a nuanced understanding of the environmental effects of property regimes. A major outcome of the synthesis will be the identification of aspects that need further, in-depth inquiry as well as policy implications of current findings.

The variety of measured outcomes and possible lack of quantitative data will delimit the applicability of statistical tools. Data will be analyzed using regression and other statistical techniques (as far as possible) to complement qualitative, narrative analysis. The review will also explore whether or not to include sources for which a significant (33\%-50\%) portion of the data are missing as done in other relevant systematic reviews [13]. Finally, a sensitivity analysis will be conducted to synthesize the conclusions of studies that did not meet quality assessment standards, and consider differences (if any) from the results of those studies that were included in the 
final review. This will be done quantitatively if the data is so presented, or otherwise will be synthesized through qualitative methods using the same data extraction matrix.

It is well known that in many research areas papers are more likely to be published if they demonstrate clear, positive results (or strong negative effects), and that papers that shown little or no effect are less likely to be published than "negative". To assess the possibility of such publication bias, we are conducting searches of 'grey' literature (much of it not formally published) in addition to studies in academic journals [28] will assess whether there is evidence of publication bias. If data allow, we will assess bias using funnel plots, which show effect sizes and standard error or sample sizes [29].

\section{Appendix}

\section{Glossary of key definitions and terms used in the review protocol}

Forest: Land with tree crown cover (or equivalent stocking level) of more than 10 percent and area of more than 0.5 hectares (ha). The trees should be able to reach a minimum height of 5 meters $(\mathrm{m})$ at maturity. A forest may consist either of closed forest formations where trees of various storeys and undergrowth cover a high proportion of the ground or open forest formations with a continuous vegetation cover in which tree crown cover exceeds 10 percent [30].

Wooded lands (woodland): Land either with a crown cover (or equivalent stocking level) of 5-10 percent of trees able to reach a height of $5 \mathrm{~m}$ at maturity, or a crown cover (or equivalent stocking level) of more than 10 percent of trees not able to reach a height of $5 \mathrm{~m}$ at maturity in situ (e.g. dwarf or stunted trees), or with shrub or bush cover of more than 10 percent. Wooded lands are included in this definition of forests [30].

Fishery: A geographical place, activity, or unit that is involved in raising and/or harvesting fish. As a unit, a fishery is typically defined in terms of some or all of the following: people involved, species or type of fish, area of water or seabed, method of fishing, class of boats and purpose of the activities [31].

Rangeland: Land on which the indigenous vegetation is predominantly grasses, grass-like plants, forbs, or shrubs and is managed as a natural ecosystem. If plants are introduced, they are managed similarly. Rangelands included natural grasslands, savannas, shrublands, many deserts, tundras, alpine communities, marshes and meadows" [32].

Property rights: A property right is an enforceable claim to use, control or otherwise benefit from a resource $[33,34]$. Property rights is often made up of a bundle of multiple rights (and responsibilities) including [19]:

- Access is the right to enter a defined physical property
- Withdrawal is the right to enter a defined physical area and obtain resource units or products of a resource system (e.g., cutting firewood or timber, harvesting mushrooms, diverting water)

- Management is the right to regulate internal use patterns and transform the resource by making improvements (e.g., planting seedlings and thinning trees)

- Exclusion is the right to determine who will have right of withdrawal and how that right may be transferred

- Alienation is the right to sell or lease withdrawal, management, and exclusion rights.

The bundle of rights also include the right to earn income from a resource even without using it directly and is derived from permitting others to use the resource $[35,36]$.

Property rights regime: a system of rules governing access to and control over resources [20]. Rules specify permissible and forbidden actions in relation to use and management, responsibilities and obligations [2,21]. The holder of a property right can be an individual, a corporation, a group or the state/government:

a) Private property: Individual or "legal individual" holds rights.

b) Common property: group members hold rights (e.g. community)

c) Public property: state holds the rights

d) No-property or Open access: no one has rights and everyone can use the resource as they like; no effective management or regulation

\section{List of developing countries included in the analysis}

Income groups correspond to 2012 gross national income (GNI) per capita (World Bank Atlas method) [37]. We will take account of country name changes since 1990 in searching for studies from the relevant countries [38].

\section{Low-income economies (\$1,035 or less)}

Afghanistan, Bangladesh, Benin, Burkina Faso, Burundi, Cambodia, Central African Republic, Chad, Comoros, Congo, Dem. Rep, Eritrea, Ethiopia, Gambia, Guinea, Guinea-Bisau, Haiti, Kenya, Kyrgyz, Liberia, Madagascar, Malawi, Mali, Mozambique, Myanmar, Nepal, Niger, Rwanda, Sierra Leone, Somalia, South Sudan, Tajikistan, Tanzania, Togo, Uganda, Zimbabwe.

\section{Lower-middle-income economies $\mathbf{( \$ 1 , 0 3 6}$ to $\$ 4,085)$}

Armenia, Bhutan, Bolivia, Cameroon, Cape Verde, Côte d'Ivoire, Djibouti, Egypt, El Salvador, Georgia, Ghana, Guatemala, Guyana, Honduras, Indonesia, India, Kiribati, Laos, Lesotho, Mauritania, Micronesia, Mongolia, Morocco, Nicaragua, Nigeria, Pakistan, Papua, Paraguay, Philippines, 
Samoa, Sao Tome, Senegal, Solomon Islands, Sri Lanka, Sudan, Swaziland, Syrian Arab Republic, Timor-Leste, Uzbekistan, Vanuatu, Vietnam, West Bank and Gaza, Yemen, Zambia.

Upper-middle-income economies $(\$ 4,086$ to $\$ 12,615)$

Angola, Algeria, Samoa, Argentina, Azerbaijan, Belize, Botswana, Brazil, China, Colombia, Costa Rica, Cuba, Dominica, Dominican Republic, Ecuador, Fiji, Gabon, Grenada, Iran, Iraq, Jamaica, Jordan, Kazakhstan, Lebanon, Libya, Malaysia, Maldives, Marshall Islands, Mauritius, Mexico, Namibia, Palau, Panama, Peru, Seychelles, South Africa, St. Lucia, St. Vincent and the Grenadines, Suriname, Thailand, Tonga, Tunisia, Turkey, Turkmenistan, Tuvalu, Venezuela.

\section{Documentation of search term testing conducted in $C A B$, Google Scholar and WOK}

Testing process with search terms for CAB, Google Scholar and WOK. The search was conducted in the online CAB, Google Scholar and WOK databases by the authors WZ and MO, see table for detailed search terms, results, dates and comments on results.

CAB Database: note that the preferred term for tenure is tenure systems; other dictionary terms include: common property resources, common lands, coownership, property rights; ownership on its own not useful This search was amended 12.5.2014.to include Descriptors and geographic locations based on reviewer suggestions.Symbol * notes truncation in order to retrieve various endings

Search Changes

1

Searched 2nd and 3rd lines in al fields rather than restricted to subject field alone
Search terms

Subject:(forest* OR fish* OR marine OR rangeland* OR grassland* OR pasture*) AND subject:(collective OR comm? $\mathrm{n}^{*}$ OR customary OR state OR public OR government OR private OR participat* OR collaborative OR cooperative OR coownership) AND subject:("tenure systems" OR property OR "property rights" OR "property regime" OR "property system" OR "common property resources" OR common lands) AND yr:[1990 TO 2013]

Subject:(forest* OR fish* OR marine OR rangeland* OR grassland* OR pasture*) AND subject:(collective OR comm? $\mathrm{n}^{*}$ OR customary OR state OR public OR government OR private OR participat* OR collaborative OR cooperative OR coownership) AND subject:("tenure systems" OR property OR "property rights" OR "property regime" OR "property system" OR "common property resources") AND yr:[1990 TO 2013]

Subject:(forest* OR fish* OR marine OR rangeland* OR grassland* OR pasture*) AND (collective OR comm? n* OR customary OR state OR public OR government OR private OR participat* OR collaborative OR cooperative OR coownership) AND ("tenure systems" OR property OR "property rights" OR "property regime" OR "property system" OR "common property resources") AND yr:[1990 TO 2013]

Subject:(forest* OR fish* OR marine OR rangeland* OR grassland* OR pasture*) AND de:(collective OR comm? $n^{*}$ OR customary OR state OR public OR government OR private OR participat* OR collaborative OR cooperative OR coownership) AND de:("tenure systems" OR property OR
Search results

2,133 results; appears somewhat relevant although many soil/plant biology entries (OXFORD)

2,409 results; still many irrelevant biological studies (OXFORD)

5,047 results; too many irrelevant results (OXFORD)

55 results; Very focused results but may be too narrow a search (OXFORD) 


\begin{tabular}{|c|c|c|c|}
\hline & & $\begin{array}{l}\text { "property rights" OR "property regime" OR "property } \\
\text { system" OR "common property resources") AND } \\
\text { yr:[1990 TO 2013] }\end{array}$ & \\
\hline 5 & $\begin{array}{l}\text { Changed } 2 \text { nd and } 3 r d \text { line fields } \\
\text { back to subject; removed collective } \\
\text { and property; added traditional }\end{array}$ & $\begin{array}{l}\text { Subject:(forest* OR fish* OR marine OR rangeland* OR } \\
\text { grassland* OR pasture*) AND subject:(comm? } n^{*} \text { OR } \\
\text { customary OR traditional OR state OR public OR } \\
\text { government OR private OR participat* OR collaborative OR } \\
\text { cooperative OR coownership) AND subject:("tenure } \\
\text { systems" OR "property rights" OR "property regime" OR } \\
\text { "property system" OR "common property resources") }\end{array}$ & $\begin{array}{l}64 \text { results; too few even without time } \\
\text { limits! (OXFORD) }\end{array}$ \\
\hline 6 & Added property* and right* & $\begin{array}{l}\text { Subject:(forest* OR fish* OR marine OR rangeland* OR } \\
\text { grassland* OR pasture*) AND subject:(comm? n* OR } \\
\text { customary OR traditional OR state OR public OR } \\
\text { government OR private OR participat* OR collaborative OR } \\
\text { cooperative OR coownership) AND subject:("tenure } \\
\text { systems" OR property* OR right* OR "property rights" OR } \\
\text { "property regime" OR "property system" OR "common } \\
\text { property resources") }\end{array}$ & $\begin{array}{l}3559 \text { results; again much noise comes } \\
\text { in; traditional often refers to medicine/ } \\
\text { plants (OXFORD) }\end{array}$ \\
\hline 7 & Removed traditional & $\begin{array}{l}\text { Subject:(forest* OR fish* OR marine OR rangeland* OR } \\
\text { grassland* OR pasture*) AND subject:(comm? } \mathrm{n}^{*} \text { OR } \\
\text { customary OR state OR public OR government OR private } \\
\text { OR participat* OR collaborative OR cooperative OR } \\
\text { coownership) AND subject:("tenure systems" OR property* } \\
\text { OR right* OR "property rights" OR "property regime" OR } \\
\text { "property system" OR "common property resources") }\end{array}$ & $\begin{array}{l}\text { 2,509 results; results appear mostly } \\
\text { relevant (many articles are from US, } \\
\text { and should be easy to discard) } \\
\text { (OXFORD) }\end{array}$ \\
\hline 8 & Added yr:[1990-2013] & $\begin{array}{l}\text { Subject:(forest* OR fish* OR marine OR rangeland* OR } \\
\text { grassland* OR pasture*) AND subject:(comm? n* OR } \\
\text { customary OR state OR public OR government OR private } \\
\text { OR participat* OR collaborative OR cooperative OR } \\
\text { coownership) AND subject:("tenure systems" OR property* } \\
\text { OR right* OR "property rights" OR "property regime" OR } \\
\text { "property system" OR "common property resources") }\end{array}$ & $\begin{array}{l}2446 \text { results, showing that most relevant } \\
\text { articles were written in review time span } \\
\text { (OXFORD) }\end{array}$ \\
\hline 9 & Added yr:[1990-2013] & $\mid \mathrm{BI}$ & \\
\hline 10 & Changed yr:[2008-2013] & $\mid \mathrm{BID}$ & 4,530 results \\
\hline 11 & Removed property* & $\begin{array}{l}\text { Subject:((forest* OR fish* OR marine OR rangeland* OR } \\
\text { grassland* OR pasture*)) AND subject:((comm? } n^{*} \text { OR } \\
\text { customary OR state OR public OR government OR private } \\
\text { OR participat* OR collaborative OR cooperative OR } \\
\text { coownership)) AND subject:(("tenure systems" OR "property } \\
\text { rights" OR "property regime" OR "property system" OR } \\
\text { "common property resources")) }\end{array}$ & 1,668 results \\
\hline 12 & Added yr:[2008 TO 2013] & $\mid \mathrm{BID}$ & 509 results \\
\hline 13 & $\begin{array}{l}\text { Removed search string of } \\
\text { regimetype }\end{array}$ & $\begin{array}{l}\text { Subject:(forest* OR fish* OR marine OR rangeland* OR } \\
\text { grassland* OR pasture*) AND subject:("tenure systems" OR } \\
\text { "property rights" OR "property regime" OR "property } \\
\text { system" OR "common property resources") }\end{array}$ & 2351 results; looks very relevant \\
\hline 14 & Added yr:[2008 TO 2013] & $\mid \mathrm{BID}$ & 723 results \\
\hline
\end{tabular}

Google Scholar (English)

Search Changes

1

\section{Search terms}

(forest $O R$ fish $O R$ marine $O R$ rangeland $O R$ grassland OR pastoralis OR pasture) AND (collective OR common OR community OR communal OR small-scale OR customary OR state OR public OR government OR private OR privatized OR company OR concession) AND (decentralization OR decentralize OR reform OR tenure OR allocation OR ownership OR property OR property right OR property regime $O R$ property system)

\section{Search results}

Search date

8000 hits on Google Scholar, but bias towards decentralization studies
9.2.2013 


\section{(Continued)}

2 Deleted small-scale, customary, decentralization, decentralize

Deleted community, privatized, company, concession, reform, property right, property regime, property system

Changed order of resource systems, added fisheries

Added property right, property regime again

Enclosed phrases "property right", "property regime" is parentheses, deleted common

Readded common

Readded community, manage, property system Removed allocation, ownership

Removed collective, replaced manage with management

Added rights terms: access, withdrawal, exclusion, exclude, alienate, alienation (forest $O R$ fish $O R$ marine $O R$ rangeland $O R$ grassland OR pastoralis OR pasture) AND (collective OR common OR community OR communal OR state OR public OR government OR private OR privatized OR company OR concession) AND (reform OR tenure OR allocation OR ownership OR property OR property right $\mathrm{OR}$ property regime $\mathrm{OR}$ property system)

(forest $\mathrm{OR}$ fish $\mathrm{OR}$ marine $\mathrm{OR}$ rangeland $\mathrm{OR}$ grassland OR pasture) AND (collective OR common OR communal OR state OR public OR government OR private) AND (tenure OR allocation OR ownership OR property)

(fish $O R$ fisheries $O R$ marine $O R$ rangeland $O R$ grassland OR pasture OR forest) AND (collective OR common OR communal OR state OR public OR government OR private) AND (tenure OR allocation OR ownership OR property)

(fish $\mathrm{OR}$ fisheries $\mathrm{OR}$ marine $\mathrm{OR}$ rangeland $\mathrm{OR}$ grassland OR pasture OR forest) AND (collective OR common OR communal OR state OR public OR government OR private) AND (tenure OR allocation OR ownership OR property OR property right $\mathrm{OR}$ property regime)

(fish $O R$ fisheries $O R$ marine $O R$ rangeland $O R$ grassland OR pasture OR forest) AND (collective OR communal OR state OR public OR government OR private) AND (tenure OR allocation OR ownership OR property OR (property regime) OR (property right))

(fish $O R$ fisheries $O R$ marine $O R$ rangeland $O R$ grassland OR pasture OR forest) AND (collective OR common OR communal OR state OR public OR government OR private) AND (tenure OR allocation OR ownership OR property OR (property right) $\mathrm{OR}$ (property regime))

(fish $O R$ fisheries $O R$ marine $O R$ rangeland $O R$ grassland OR pasture OR forest) AND (collective OR common OR communal OR community OR state OR public OR government OR private) AND (tenure OR manage OR property OR (property right) OR (property regime) OR (property system))

(fish $O R$ fisheries $O R$ marine $O R$ rangeland $O R$ grassland OR pasture OR forest) AND (common OR communal OR community OR state OR public OR government OR private) AND (tenure OR management OR property OR (property right) OR (property regime) OR (property system))

(fish $O R$ fisheries $O R$ marine $O R$ rangeland $O R$ grassland OR pasture OR forest) AND (common OR communal OR community OR state OR public OR government OR private) AND (tenure OR property OR (property right) OR (property regime) OR (property system)) AND (management OR access OR withdrawal OR exclusion OR exclude OR alienate OR alienation)

(fish OR fisheries OR rangeland OR grassland OR pasture OR forest) AND (common OR community OR state OR public OR government OR private) AND (tenure OR property)
Reform brings a lot of noise

9222013

Good first 20-30 results

More results for fisheries

Much fewer, narrower results

(around 450,000) - but great emphasis on common property, delimitation by time range further narrows results

Many more results with the phrase "property right" in initial search results; some do not appear relevant to environmental issues

Many more results with "common property", as found in search 5

Common property still come to the top of search results, collective seems to bring up mosty collective action results

Results are not too different

Results are not well targeted; limitation by time (2008-present) makes results more irrelevant
Removed rights terms, communal, property right, property regime, property system 


\section{(Continued)}

\begin{tabular}{|c|c|c|c|c|}
\hline 12 & Added rights & $\begin{array}{l}\text { (fish OR fisheries OR rangeland OR grassland OR } \\
\text { pasture OR forest) AND (common OR } \\
\text { community OR government OR state OR public } \\
\text { OR private) AND (tenure OR property OR rights) }\end{array}$ & $\begin{array}{l}\text { Emphasis on common property, } \\
\text { community management, but first } \\
\text { pages of search results look good }\end{array}$ & 9.3 .2013 \\
\hline 13 & Added management & $\begin{array}{l}\text { (fish OR fisheries OR rangeland OR grassland OR } \\
\text { pasture OR forest) AND (common OR } \\
\text { community OR government OR state OR public } \\
\text { OR private) AND (tenure OR property OR rights } \\
\text { OR management) }\end{array}$ & $\begin{array}{l}\text { Management gives broad policy } \\
\text { results }\end{array}$ & 9.3 .2013 \\
\hline 14 & $\begin{array}{l}\text { Removed management, added } \\
\text { ownership }\end{array}$ & $\begin{array}{l}\text { (fish OR fisheries OR rangeland OR grassland OR } \\
\text { pasture OR forest) AND (common OR } \\
\text { community OR government OR state OR public } \\
\text { OR private) AND (tenure OR property OR rights } \\
\text { OR ownership) }\end{array}$ & $\begin{array}{l}\text { Ownership adds no new results of } \\
\text { pertinence }\end{array}$ & 9.3 .2013 \\
\hline
\end{tabular}

WOK database

Symbol $\left(^{*}\right)$ notes truncation in order to retrieve various endings

stock OR resource OR population AND common* AND property

fish* OR forest* OR rangeland* OR pasture OR cattle AND comm* AND govern* AND property OR right*

fish*, forest*, rangeland*, pasture, cattle AND common OR community OR private OR shared AND access OR management

fish*OR forest* OR rangeland* OR pasture OR cattle AND common property OR common-pool OR privat* AND access OR management AND effect* AND benefit*

fish*OR forest* OR rangeland*, pasture OR cattle AND common OR private OR shared AND property OR rights OR quota* OR tenure $O R$ title OR deed

fish* OR forest* OR pasture OR rangeland* OR cattle AND tenure or reform or regime or rule* or quota* or customary AND impact* OR effect* OR effectiveness OR benefit* AND common property or "common-pool" or "community-based" or state or private "community-controlled" AND access or management or use* or withdrawal or harvest or monitor

fish* OR forest* OR pasture OR rangeland* OR cattle AND tenure or reform or property or rule* or quota* or custom* or transfer* AND impact* OR effect* OR benefit* AND common property or "commonpool" or "community-based" or state or private "communitycontrolled" AND access* or management or harvest* or monitor*

fish* OR forest* OR pasture OR rangeland* OR cattle AND tenure or reform or property or governance or quota* or custom* or transfer* AND impact* OR effect* OR benefit* AND common property or "common-pool" or "community-based" or state or private

"community-controlled" AND access* or management or harvest* or monitor*

fish* OR forest* OR pasture OR rangeland* OR cattle AND tenure or reform or property or govern* or quota* or custom* AND impact* OR effect* OR benefit* AND common property or "common-pool" or "community-based" or state or private or "community-controlled" or "open-access" AND access* or management or harvest* or monitor*

fish* OR forest* OR pasture OR rangeland* OR cattle AND tenure or reform or govern* or quota* or custom* AND impact* OR effect* OR benefit* AND common property or " common-pool" or "communitybased" or state or private or "community-controlled" or "open-access" AND access* or management or harvest* or monitor*

fish* OR forest* OR pasture OR rangeland* OR cattle AND tenure or reform or govern* or custom* AND right* or ownership* AND

\begin{tabular}{|c|c|c|}
\hline Hits & Date & Comments \\
\hline 6637 & 16.4.2013 & $\begin{array}{l}\text { Obviously needs a better description of } \\
\text { the resource }\end{array}$ \\
\hline 1463 & 16.4.2013 & still too much noise \\
\hline 88308 & 22.4 .2013 & Management brings noise \\
\hline 3301 & 22.4.2013 & Seem relevant \\
\hline 28971 & 22.4 .2013 & Too huge number \\
\hline 4914 & 24.4.2013 & Seem relevant \\
\hline 5064 & 24.4.2013 & Rules leads to misleading results \\
\hline 4702 & 24.4.2013 & $\begin{array}{l}\text { Replaced rules with governance, transfer } \\
\text { still brings misleading results }\end{array}$ \\
\hline 6919 & 24.4.2013 & $\begin{array}{l}\text { Changed governance into govern*, } \\
\text { removed transfer }\end{array}$ \\
\hline 4001 & 24.4.2013 & Removed property because it brings noise \\
\hline 938 & 25.4.2013 & Remove state, private and quota \\
\hline
\end{tabular}


common property or " common-pool" or "community-based" or "community-controlled" or "open-access"

fish* OR forest* OR pasture OR rangeland* OR cattle AND tenure or reform or govern* or custom* AND common property or "commonpool" or "community-based" or "community-controlled" or "openaccess" AND biodivers* or divers* or loss or deplet* or deforestation or conservation AND sustainab*

fish* OR forest* OR pasture OR rangeland* OR cattle AND tenure or reform or govern* or custom* AND common property or "commonpool" or "community-based" or "community-controlled" or "openaccess" or private or state AND biodivers* or divers* or loss or deplet* or deforestation or conservation or benefit* AND sustainab*

fish* OR forest* OR pasture OR rangeland* OR cattle AND biodivers* or divers* or loss or deplet* or deforestation or degradation or conservation AND benefit* or sustainab* or improv* or effect* AND tenure or regime or management or access or right AND tenure or reform or governance or customary

rangeland OR pasture or pastoralist* AND biodivers* or divers* or loss or deplet* or deforest* or degradat* or conservation AND benefit* or sustainab* or improv* or effect* AND community-based or "community-controlled" or "open-access" or enclosure

rangeland OR pasture or pastoralist* AND biodivers* or divers* or loss or deplet* or overgraz* or degradat* or conservation AND benefit* or sustainab* or improv* or effect* AND community-based or community-controlled or open-access or tenure or property or collective

rangeland OR pasture or pastoralist* AND biodivers* or divers* or loss or deplet* or overgraz* or degradat* or conservation AND benefit* or sustainab* or improv* or effect* AND community-based or community-controlled or open-access or tenure or property rights or collective

rangeland OR pasture or pastoralist* AND biodivers* or divers* or loss or deplet* or overgraz* or degradat* or conservation AND benefit* or sustainab* or improv* or effect* AND community or open-access or tenure or property rights or collective or privatization

rangeland OR pasture or pastoralist* AND biodivers* or divers* or loss or deplet* or overgraz* or degradat* or conservation AND benefit* or sustainab* or improv* or effect* AND community managed or "community based" or "community controlled" or tenure or property rights or collective or privatization

rangeland OR pasture or pastoralist* AND biodivers* or divers* or loss or deplet* or overgraz* or degradat* or conservation AND benefit* or sustainab* or improv* or effect* AND community managed or "community based" or "community controlled" or tenure or property rights or collective or privatization and ranch

rangeland OR pasture or pastoralist* AND biodivers* or divers* or loss or deplet* or overgraz* or degradat* or conservation AND benefit* or sustainab* or improv* or effect* AND community based or collective or privatization or common property or tenure or property rights

fish* OR forest* OR rangeland* OR pasture OR grasslands or livestock or cattle AND property near (common or regime) or common?pool or community same ( based or manage*) or privat* or state or compan* AND tree or wood* or environment* or ecologic* OR condition or population fish* OR forest* OR rangeland* OR pasture OR grasslands or livestock or cattle AND chang* or impact* or effect* or improv* or declin* or ${ }^{*}$ crease AND tenure or allocation or ownership or right or intervention

fish* OR forest* or marin* AND property same (common or regime) or common?pool or community same ( based or manage*) or privat* or state or compan* AND forest or timber or tree or environment* or ecologic* OR condition or population or fish* or stock AND impact* or effect* or improv* $^{*}$ or deplet* or conserv* or sustainab* AND tenure or allocation or ownership or intervention or quota
Inserted environmental outcomes and sustainability, because many articles did not mention environmental outcomes

Added state and private

Testing with sustainability indicators

Trying with rangeland and pasture and pastoralist. Management brings too much noise, also enclosure needs a more descriptive attribute

Removing enclosure and adding overgrazing

30.4.2013 Inserting property rights

inserting just community and privatization

Community-based returns a lot of relevant looking results

Adding ranch brings some good articles not so many

Seems relevant, but still not discussing environmental outcomes that much
Cattle and livestock bring a lot of noise, maybe a separate search needs to be done on the 


\section{(Continued)}

fish* or marine AND customary or small?scale or (property right*) or (common property) or tenure or (open access) AND resource* or population or size or stock or catch or specie* or biomass AND access or manag* or harvest*

forest* AND comm?n* or community* or privat* or state or compan* or concession* or compan* or collective AND tree* or wood* or environment* or ecologic ${ }^{*}$ OR condition* or biodiversity or specie* or forest* or resource AND chang* or impact* or effect* or improv* or declin* or ${ }^{*}$ crease AND decentraliz* or tenure or allocation or ownership or intervention or reform or (property rights) or property regime or management

forest* or property rights or tenure AND comm?n* or community* or privat* or state or compan* or concession* or compan* or collective AND tree* or wood* or environment* or ecologic* OR condition* or biodiversity or specie* or forest* or resource AND chang* or impact*

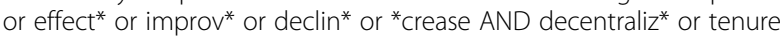
or allocation or ownership or intervention or reform or property rights or property regime or management

grassland* or pastoralist or pasture or livestock AND comm?n* or state or privat* AND property rights or tenure or property regime $A D$ animal* or land or environment* or vegetation or composition or species

forest $^{*}$ or fish* or marine or grassland* or pastoralis* or pasture or rangeland* AND decentraliz ${ }^{*}$ or tenure or reform* or allocation or ownership or "property right"or "property rights" or "property regime" or "property system" or manag* or access or harvest* or open?access AND collective or comm? $n^{*}$ or small?scale or customary or state or public or privat* or compan* or concession* or participat* or collaborative or co?operative or co-manage* or shared or joint AND Afghan* or Bangladesh* or Benin* or Burkina* or Burundi* or Cambodia* or Central African Republic or Chad* or Comoro* or Congo* or Eritrea* or Ethiopia* or Gambia* or Guinea* or Haiti* or Kenya* or Korea* or Kyrgyz* or Liberia* or Madagascar* or Malagasy* or Malawi* or Mali* or Mozambique* or Myanmar* or Burma* or Nepal* or Niger* or Rwanda* or Sierra Leone or Somali* or Sudan* or Tajikistan* or Tanzania* or Togo* or Uganda* or Zimbabwe*

forest* or fish* or marine or grassland* or pastoralist* or pasture or rangeland AND decentraliz* or tenure or allocation or ownership or reform or (property rights) or property regime or management* AND collective or comm? $\mathrm{n}^{*}$ or small?scale or customary or state or public or privat* or compan* or concession* or participat* or collaborative or cooperative or co-manage* AND Angola* or Algeria* or Samoa* or Argentina* or Azerbaijan* or Beliz* or Botswana* or Brazil ${ }^{*}$ or Chin* or Colombia* or "Costa Rica" or "Costa Rican" or Cuba* or Dominica* or Equatorian* or Ecuador* or Fiji* or Gabon* or Grenad* or Iran* or Iraq* or Jamaica * or Jordan* or Kazak* or Leban* or Libya* or Malaysia* or Maldives or "Marshall Islands" or Mayotte or Mauritius or Mexic* or Namibia* or Palau* or Panama* or Peru * or Seychell* or "South Africa" or "St. Lucia" or "St. Vincent" or Suriname* or Thai* or Tonga* or Tunisia* or Turk* or Turkmenistan* or Tuvalu* or Venezuela*

forest* or fish* or marine or grassland* or pastoralis* or pasture or rangeland* AND decentraliz* or tenure or reform* or allocation or ownership or "property right"or "property rights" or "property regime" or "property system" or manag* or access or harvest* or open?access AND collective or comm? $n^{*}$ or small?scale or customary or state or public or privat* or compan* or concession* or participat* or collaborative or cooperative or co-manage* or shared or joint AND Angola* or Algeria* or Samoa* or Argentina* or Azerbaijan* or Beliz* or Botswana* or Brazil* or Chin* or Colombia* or "Costa Rica" or Cuba* or Dominica* or Ecuador* or Fiji* or Gabon* or Grenad* or Iran* or Iraq* or Jamaica * or Jordan* or Kazak* or Leban* or Libya* or Malaysia* or Maldives or "Marshall Islands" or Mayotte or Mauritius or Mexic ${ }^{*}$ or Namibia* or Palau* or Panama* or Peru* or Seychell* or "South Africa" or "St. Lucia" or "St. Vincent" or Suriname* or Thai* or Tonga* or Tunisia* or Turk* or Tuvalu* or Venezuela*
Very good, easy to exclude with words USA, Canada, Sweden

By Excluding Canada, Sweden, Finland, Mediterranean, Australia 316+150+ $133+128+245$

Stil not too many articles discussing environmental outcomes but common property regimes in general

2652 all the years/2557 (1990-2013) and 1451 2008-2013. Contains reform

7356 (1990-2013), 4241 ( 2008-2013). This search contains benchmark studies identified 


\section{Competing interests}

The authors do not declare any conflicts of interest. This research is funded by the Center for International Forestry Research (CIFOR).

\section{Authors' contributions}

EM developed the research question. MO \& WZ conducted pilot research. $M O, D C M, W Z, B M$ and EM wrote the protocol with support from GP. All the authors $\mathrm{MO}, \mathrm{DCM}, \mathrm{WZ}, \mathrm{BM}, \mathrm{EM}$ and GP read and approved the final manuscript.

\section{Acknowledgements}

The review team would like to thank Eduardo Araral Jr., Eduardo Brondizio, Anne Larson, Monica Lengoiboni, Michael Mascia, Maryam Niamir-Fuller, Frank Place, and William Sunderlin, for their time and comments on an earlier draft of this research protocol. The review team would also like to thank the Center for International Forestry Research (CIFOR) and the UK Department for International Development (DfID) for financing this research through its KNOW-FOR program grant.

\section{Author details}

${ }^{1}$ Center for International Forestry Research (CIFOR), Jalan CIFOR, Situ Gede, Sindang Barang, Bogor (Barat) 16115, Indonesia. ${ }^{2}$ School of Natural Resources and Environment, University of Michigan, 4024 Dana Building, 440 Church Street, Ann Arbor, Ml 48109, USA. ${ }^{3}$ Department of Zoology, The Tinbergen Building, South Parks Road, Oxford OX1 3PS, UK.

Received: 27 March 2014 Accepted: 25 July 2014

Published: 19 September 2014

\section{References}

1. Hardin G: The tragedy of the commons. Science 1968, 162:1243-1248.

2. Ostrom E: Governing the Commons: The Evolution of Institutions for Collective Action. Cambridge: Cambridge University Press; 1990.

3. Larson AM, Soto F: Decentralization of Natural Resource Governance Regimes. Annu Rev Environ Resour 2008, 33:213-239.

4. Ostrom $\mathrm{E}$, Nagendra $\mathrm{H}$ : Insights on linking forests, trees, and people from the air, on the ground, and in the laboratory. Proc Natl Acad Sci 2006 , 103:19224-19231.

5. Besley T, Burgess R: Land reform, poverty reduction, and growth:evidence from India. Q J Econ 2000, 115:389-430

6. Meinzen-Dick RS, Brown LR, Feldstein HS, Quisumbing AR: Gender, property rights, and natural resources. World Dev 1997, 25:1303-1315.

7. Berkes F: Community conserved areas: policy issues in historic and contemporary context. Conserv Lett 2009, 2:19-24.

8. Sunderlin WD, Larson AM, Cronkleton P: Forest Tenure Rights and REDD+ From Inertia to Policy Solutions. In Realising REDD+: National Strategy and Policy Options. Bogor, Indonesia: Center for International Forestry Research (CIFOR); 2009:139-149.

9. Lemos MC, Agrawal A: Environmental Governance. Annu Rev Environ Resour 2006, 31:297-325.

10. Dahal GR, Larson AM, Pacheco P: Outcomes of Reforms for Livelihoods, Forest Condition and Equity. In Forests for People: Community Rights and Forest Tenure Reform. London, UK: Earthscan; 2010:183-208.

11. Costello C, Gaines SD, Lynham J: Can catch shares prevent fisheries collapse? Science 2008, 321:1678-1681.

12. Homewood KM: Policy, environment and development in African rangelands. Environ Sci Pol 2004, 7:125-143.

13. Brooks J, Waylen KA, Borgerhoff Mulder M: Assessing community-based conservation projects: A systematic review and multilevel analysis of attitudinal, behavioral, ecological, and economic outcomes. Environ Evid 2013, 2

14. Evans L, Cherrett N, Pemsl D: Assessing the impact of fisheries co-management interventions in developing countries: a meta-analysis. J Environ Manage 2011, 92:1938-1949.

15. Hellebrandt D, Sikor T, Hooper L: Rigorous Literature Review. Is the use of Renewable Natural Resources in the Developing World more or less Sustainable, Pro-Poor and Profitable under Controlled Access compared to Open Access. Norwich, UK: International Development UEA -DEVCo; 2012:1-98.

16. Sayer J, Sunderland T, Ghazoul J, Pfund J-L, Sheil D, Meijaard E, Venter M, Boedhihartono AK, Day M, Garcia C: Ten principles for a landscape approach to reconciling agriculture, conservation, and other competing land uses. Proc Natl Acad Sci 2013, 110:8349-8356.

17. Larson AM, Barry D, Dahal GR, Colfer CJP: Forests for People: Community Rights and Forest Tenure Reform. London: Earthscan; 2010.

18. CEE: Guidelines for Systematic Reviews in Environmental Management (version 4.2). Collaboration Environ Evid 2013, 1-80.

19. Schlager E, Ostrom E: Property-Rights Regimes and Natural Resources: A Conceptual Analysis. Land Econ 1992, 68:249-262.

20. Waldron J: The Right to Private Property. Oxford: Clarendon Press; 1988.

21. Bromley DW: Environment and Economy: Property Rights and Public Policy. Oxford: Blackwell; 1991

22. Smith EP: BACI design. Encyclopedia Environ 2006, 1:141-148.

23. Porter-Bolland L, Ellis EA, Guariguata MR, Ruiz-Mallen I, Negrete-Yankelevich S, Reyes-Garcia V: Community managed forests and forest protected areas: An assessment of their conservation effectiveness across the tropics. For Ecol Manag 2012, 268:6-17.

24. Robinson BE, Holland MB, Naughton-Treves L: Does Secure Land Tenure Save Forests? A Review of the Relationship between Land Tenure and Tropical Deforestation. In CCAFS Working Paper. CGIAR Research Program on Climate Change, Agriculture and Food Security; 2011.

25. Shahabuddin G, Rao M: Do community-conserved areas effectively conserve biological diversity? Global insights and the Indian context. Biol Conserv 2010, 143:2926-2936

26. Higgins J, Green S: Cochrane Handbook for Systematic Reviews of Interventions. The Cochrane Collaboration; 2008.

27. Sikor T, Lund C: Access and property: a question of power and authority. Dev Chang 2009, 40:1-22.

28. Leimu R, Koricheva J: What determines the citation frequency of ecological papers? Trends Ecol Evol 2005, 20:28-32.

29. Sterne JA, Egger M: Funnel plots for detecting bias in meta-analysis: guidelines on choice of axis. J Clin Epidemiol 2001, 54:1046-1055.

30. Terms and Definitions-Global Forest Resources Assessment. [http://www. fao.org/docrep/006/ad665e/ad665e06.htm]

31. Fisheries Glossary online. [http://www.fao.org/fi/glossary/]

32. Glossary of Terms used in Range Management. [https://globalrangelands. org/rangelandswest/glossary]

33. Bromley DW, Cernea MM: The Management of Common Property Natural Resources: Some Conceptual and Operational Fallacies. Volume 57. World Bank Discussion Papers; 1989.

34. Macpherson CB: Property, Mainstream and Critical Positions. Toronto, Canada: University of Toronto Press; 1978

35. Eggertsson T: Economic Behavior and Institutions. Cambridge, U.K.: Cambridge University Press; 1990

36. Honore AM: Ownership. Oxford: Oxford University Press; 1961

37. World Bank Country Classifications. 2013

38. Timeline of Country and Capital Changes. [http://en.wikipedia.org/wiki/ Timeline_of_country_and_capital_changes]

doi:10.1186/2047-2382-3-19

Cite this article as: Ojanen et al:: What are the environmental impacts of property rights regimes in forests, fisheries and rangelands? a systematic review protocol. Environmental Evidence 2014 3:19.

\section{Submit your next manuscript to BioMed Central and take full advantage of:}

- Convenient online submission

- Thorough peer review

- No space constraints or color figure charges

- Immediate publication on acceptance

- Inclusion in PubMed, CAS, Scopus and Google Scholar

- Research which is freely available for redistribution 